\title{
Surgical repair of corneal laceration complicated by iris inclusion in a dog
}

Sherin B. Sarangom, Nithina K. Baburaj, Thomas Edison D'Sa ${ }^{1}$,Syam K. Venugopal

Department of Veterinary Surgery and Radiology

College of Veterinary and Animal Sciences, Mannuthy, Thrissur, Kerala - 680651, India.

Corresponding author: Sherin B. Sarangom, email: sbs04vet@gmail.com

Received: 24-03-2012, Accepted: 25-04-2012, Published Online: 29-07-2012

doi: $10.5455 /$ vetworld.2012.631-633

\section{To cite this article:}

Sarangom SB, Baburaj NK, D'Sa TE, Venugopal SK (2012) Surgical repair of corneal laceration complicated by iris inclusion in a dog, Vet World, 5(10): 624-626, doi: 10.5455/vetworld.2012.631-633

\section{Introduction}

The prolapsed iris through a corneal perforation is frequently encountered in small animal practice. The condition may occur following progression of complicated corneal ulcers [1] or as a result of full thickness corneal lacerations [2]. A prolapsed iris should be treated as an ocular emergency and requires immediate surgical intervention for better prognosis. The surgical repair usually involves correct reposition of viable iris tissue or excision of the incarcerated tissue, as well as adequate closure of corneal wound [3]. The different corneal bandaging techniques using contact lenses, collagen based biomaterials, cyanoacrylate tissue adhesives, corneal graft, third eye lid flap, conjunctival flap and temporary tarsorrhaphy for the repair of full thickness defect in cornea has also been described [4]. However, traumatic prolapse of iris and its surgical repair are less frequently documented. This paper presents a case of corneal laceration complicated by iris inclusion in a dog and its surgical repair using collagen sheet prepared from bovine small intestine submucosa adjunct to corneal suturing after iris reposition.

\section{Case History and Clinical Observations}

A six month old male non-descript dog was presented to the Veterinary College Hospital, Mannuthy with the complaint of a dark brown colored mass protruding out from the right eye. History revealed trauma by a sharp object four hours ago. The animal was dull and depressed. On clinical examination, the mass was found to be iris, which got entangled in the perforated cornea at 10 O'clock position (fig. 1). The dog showed epiphora, severe blepharospasm and photophobia. Ophthalmic examination revealed distorted cornea with focal corneal oedema and fibrin clot at the site of laceration, shallow anterior chamber with hyphema, miosis and dyscoria. The pupil was found to be distorted in the direction of corneal laceration. The physiological parameters were within the normal range and the prolapsed iris tissue appeared to be fresh. Hence surgical iris reposition and corneal wound repair under general anaesthesia was resorted too.

\section{Treatment}

Topical instillation of $1 \%$ atropine sulphate ophthalmic solution was done prior to surgery to achieve mydriasis. Pre-operatively, ceftriaxone sodium was administered at the rate of $25 \mathrm{mg} / \mathrm{kg}$ body weight intravenously. The dog was premedicated with atropine sulphate at the rate of $0.045 \mathrm{mg} / \mathrm{kg}$ body weight followed by xylazine hydrochloride at the rate of $1.5 \mathrm{mg} / \mathrm{kg}$ body weight, both given intramuscularly. General anaesthesia was induced with ketamine hydrochloride at the rate of $5 \mathrm{mg} / \mathrm{kg}$ body weight, administered intramuscularly. Anaesthesia was maintained by intravenous infusion of a combination of xylazine hydrochloride and ketamine hydrochloride, equal quantity by volume and diazepam, given 'to effect' along with 5\% dextrose saline. The periocular area was carefully clipped and scrubbed with povidone iodine solution diluted with normal saline $(0.2 \%)$. The corneal and conjunctival surfaces were irrigated with isotonic balanced salt solution and the periocular area was painted with povidone iodine solution. The dog was positioned in left lateral recumbency with the eye placed under the objective lens of the operating microscope (10x). Povidone iodine $(5 \% \mathrm{w} / \mathrm{v})$ was instilled and the face was draped. The Castroviejo lid speculum was applied for better 


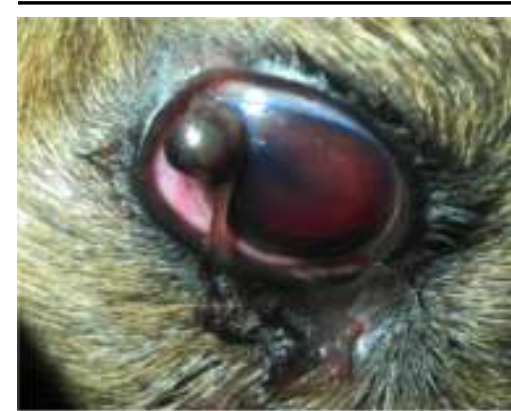

Fig. 1: Iris tissue prolapsed through the lacerated cornea

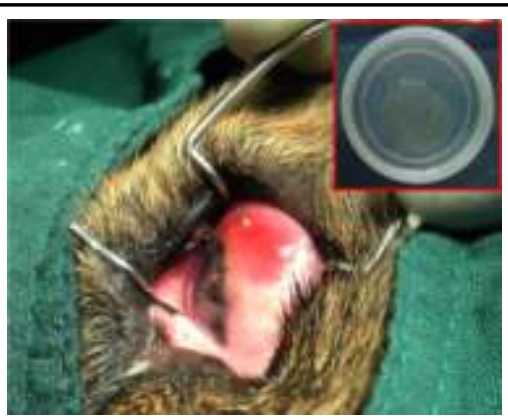

Fig. 2: Lacerated cornea after apposition. Inset shows rehydrated collagen sheet before application

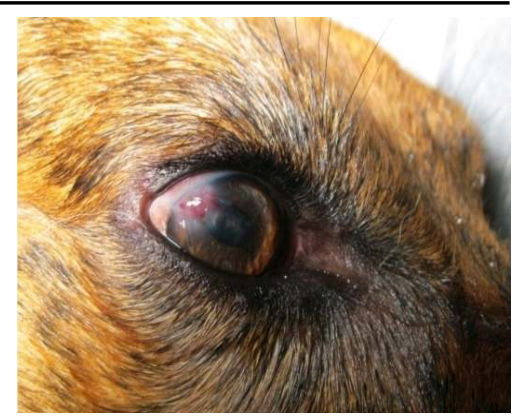

Fig. 3: Appearance of cornea on the $10^{\text {th }}$ postoperative day exposure. The adhesions between the protruded iris and cornea were gently separated and the iris was replaced back to its normal position with the help of an iris spatula. The blood clots in the anterior chamber were carefully removed by gentle flushing with balanced salt solution using an irrigation canula. The edges of corneal wound were grasped with Colibri forceps and were apposed by simple interrupted sutures using No. 6-0 monofilament polyamide without perforating the cornea completely (fig. 2). The anterior chamber was reconstituted with balanced salt solution along with a small air bubble before placing the last corneal suture. A collagen diskette prepared from submucosa of bovine small intestine was spread over the cornea after soaking with gentamicin eye drops for 15 minutes and temporary tarsorrhaphy was done.

Postoperatively, moxifloxacin eye drops (four times daily) and flurbiprofen eye drops (two times daily) were instilled for 7 days. Orally, cefixime at the rate of $10 \mathrm{mg} / \mathrm{kg}$ body weight and meloxicam at the rate of $0.2 \mathrm{mg} / \mathrm{kg}$ body weight were administered for 5 days. Elizabethan collar was used postoperatively for two weeks to prevent self mutilation. The corneal sutures were removed on the $10^{\text {th }}$ day. Mild vascularisation and opacity were noticed at the suture line (fig. 3), which resolved later and the animal had an uneventful recovery.

\section{Discussion}

Corneal injuries are common in canines, especially in puppies in which the ocular protective mechanisms like menace reflex are not fully developed. The prolapsed iris through a corneal laceration is an ocular emergency that result in severe ocular pain and may lead to loss of vision, if left untreated. According to Sansom [5], the extrusion of iris through the cornea will seal the wound, but remains as a potent tract to intraocular infection. The objects inducing full thickness lacerations penetrate the chamber rapidly and may traumatize the intraocular structures and hence require complete ophthalmic and physical examination.

In the present case, the clinical signs were similar to that reported by Mandell and Holt [6]. The reposition of iris was resorted to since the tissue was found to be fresh. The topical instillation of cycloplegic, $1 \%$ atropine sulphate solution (ophthalmic) helped to dilate the pupil and also to decrease the discomfort of the patient. Monofilament polyamide being nonirritant, non-capillary and biologically inert was preferred for suturing the cornea. The corneal sutures were placed deeply in the stroma down to the Descemet's membrane without perforating the cornea completely, as the endothelium is exquisitely sensitive to trauma [3]. Even though anaesthesia was induced with ketamine hydrochloride, the combination with diazepam for maintenance reduced the ketamine induced increase in intraocular pressure and thereby suture tension [7]. Topical instillation of flurbiprofen provided considerable analgesia and helped to control inflammation. The corneal sutures were removed on the $10^{\text {th }}$ day, although corneal wounds depend on sutures for tensile strength for at least 16 days [8]. Corneal healing with vascularisation was noticed on the $7^{\text {th }}$ day itself. Also, the collagen based biomaterial, bovine small intestine submucosa used in the present case was found to reduce the healing period of corneal defect as observed by Anoop et al. [9]. The prognosis for vision and cosmetic appearance in case of prolapsed iris and lacerated cornea is fair to good if the damaged cornea is repaired, provided the intraocular structures are not severely damaged by trauma. The complications associated with iris prolapse and corneal laceration included uveitis, endophthalmitis, panophthalmitis, anterior synechia, pigmentation, secondary glaucoma and dehiscence of suture. However, no such complications were noticed in the 
present case except for a mild opacity which resolved later.

\section{References}

1. Wilkie, D. A. and Whittaker, C. (1997). Surgery of the cornea. Vet. Clin. North Am. Small Anim. Pract. 27: $1097-1107$.

2. Ranganath, L. and Mahesh, V. (2009). Surgical correction of iris prolapse in a dog. Indian J. Vet. Surg. 30: 126.

3. Hollingsworth, S. R. (2003). Corneal surgical techniques. Clin. Tech. Small Anim. Pract. 18: 161 167.

4. Moore, P. A. (2003). Diagnosis and management of chronic corneal epithelial defects (Indolent corneal ulcerations). Clin. Tech. Small Anim. Pract. 18: 168 177.

5. Sansom, J. (2000). Diseases involving the anterior chamber of the dog and cat. In Pract. 22: 58 - 70 .

6. Mandell, D. C. and Holt, E. (2005). Ophthalmic emergencies. Vet. Clin. North Am. Small Anim. Pract. 35: $455-480$.

7. Collins, B. K., Gross, M. E., Moore, C. P. and Branson, K. R. (1995). Physiologic, pharmacologic and practical considerations for anesthesia of domestic animals with eye diseases. J. Am. Vet. Med. Assoc. 207: 220-230.

8. Slatter, D. and Dietrich, U. (2003). Cornea and Sclera. In: Text book of small animal surgery. Ed. Slatter, D. Third edn. W. B. Saunders, Philadelphia, pp: 1368 1396.

9. Anoop, S., Jose, C., Syam, K. V and Amma, T. S. (2010). Efficacy of collagen sheet for the management of staphyloma in dogs. In: Proceedings of world academy of science, engineering and technology, Singapore. 69; $131-133$. 